\title{
Pain measurement in oral and maxillofacial surgery
}

\author{
Nattapong Sirintawat, Kamonpun Sawang, Teeranut Chaiyasamut, and Natthamet Wongsirichat \\ Department of Oral and Maxillofacial Surgery, Faculty of Dentistry, Mahidol University, Bangkok, Thailand
}

\begin{abstract}
Regardless of whether it is acute or chronic, the assessment of pain should be simple and practical. Since the intensity of pain is thought to be one of the primary factors that determine its effect on a human's overall function and sense, there are many scales to assess pain. The aim of the current article was to review pain intensity scales that are commonly used in dental and oral and maxillofacial surgery (OMFS). Previous studies demonstrated that multidimensional scales, such as the McGill Pain Questionnaire, Short form of the McGill Pain Questionnaire, and Wisconsin Brief Pain Questionnaire were suitable for assessing chronic pain, while unidimensional scales, like the Visual Analogue Scales (VAS), Verbal descriptor scale, Verbal rating scale, Numerical rating Scale, Faces Pain Scale, Wong-Baker Faces Pain Rating Scale (WBS), and Full Cup Test, were used to evaluate acute pain. The WBS is widely used to assess pain in children and elderly because other scales are often difficult to understand, which could consequently lead to an overestimation of the pain intensity. In dental or OMFS research, the use of the VAS is more common because it is more reliable, valid, sensitive, and appropriate. However, some researchers use NRS to evaluate OMFS pain in adults because this scale is easier to use than VAS and yields relatively similar pain scores. This review only assessed pain scales used for post-operative OMFS or dental pain.
\end{abstract}

Keywords: McGill Pain Scale; Oral and Maxillofacial Pain; Pain Measurement; Toothache; Visual Analogue Pain Scale.

This is an Open Access article distributed under the terms of the Creative Commons Attribution Non-Commercial License (http://creativecommons.org/licenses/by-nc/4.0/) which permits unrestricted non-commercial use, distribution, and reproduction in any medium, provided the original work is properly cited.

\section{INTRODUCTION}

Pain is one of the most common complaints that patients present with at hospital [1]. Pain has several definitions that depend on the aim or scope. Mersky et al. [2] defined pain as "an unpleasant sensory and emotional experience with actual or potential tissue damage or described in terms of such damage.". McAloon et al. [3] described pain as a subjective feeling or experience interpreted by oneself, while Gloss et al. [4] reported that pain is a complex and private experience.
Briggs and Closs [5] highlighted that pain was also influenced by numerous intrinsic and extrinsic factors, and that multiple aspects of pain was assessed in different ways. Although no one interprets pain in exactly the same way, the intensity of pain depending on the patients' perception, should be assessed for effective pain management [3]. Pain perception depends on the pain threshold of each person, which might be used as a baseline to compare pain intensity.

The assessment of the intensity of pain and locating it is a routine procedure in clinical practice. Various tools have been developed for different types and subtypes of

Received: October 16, 2017 - Revised: November 28, 2017 • Accepted: November 30, 2017

Corresponding Author: Natthamet Wongsirichat, Department of Oral Maxillofacial Surgery, Faculty of Dentistry,Mahidol University 6 Yothi Street Rachathewee District Bangkok 10400 Thailand

Tel: +66022007777 ext 3333 E-mail: natthamet.won@mahidol.ac.th

Copyright(c) 2017 Journal of Dental Anesthesia and Pain Medicine 
chronic pain conditions so that the effect of chronic pain on quality of life and the patient's function can be gaged [6]. The accuracy of pain assessment is very important to evaluate the appropriate treatment.

Pain intensity is the initial factor that point to its sensation and function. Therefore, pain measurement tools are used to help assess pain intensity, and monitor the effectiveness of and response to treatment decisions [7].

Multidimensional pain scales assess the following:
a. associated factors
b. location / severity
c. chronicity
d. quality
e. contributing / distribution
f. etiology of pain, if identifiable
g. mechanism of injury, if applicable
h. barriers to pain assessment

The aim of the current article was to provide an overview of pain measurements that are commonly used in OMFS research.

\section{TYPES OF PAIN INTENSITY SCALES (Table 1)}

There are multidimensional and unidimensional scales of pain. The following are multidimensional scales:

a. McGill Pain Questionnaire (MPQ)

b. Short form of the McGill Pain Questionnaire (SF-MPQ)

c. Wisconsin Brief Pain Questionnaire (BPQ)

Unidimensional scales to assess pain are as follows:

Table 1. Pain intensity scale abbreviations

\begin{tabular}{ll}
\hline \multicolumn{1}{c}{ Variable } & \multicolumn{1}{c}{ Abbreviation } \\
\hline McGill Pain Questionnaire & $:$ MPO \\
Short form of the McGill Pain Questionnaire & : SF-MPO \\
Wisconsin Brief Pain Questionnaire & $:$ BPO \\
Visual Analogue Scales & $:$ VAS \\
Verbal descriptor scale & $:$ VDS \\
Verbal rating scale & $:$ VRS \\
Numerical rating Scale & $:$ NRS \\
Faces Pain Scale & $:$ FPS \\
Wong-Baker Faces Pain Rating Scale & $:$ WBS \\
Full Cup Test & $:$ FCT \\
\hline
\end{tabular}
a. Visual Analogue Scales (VAS)
b. Heft-Parker visual analog scale (HPS)
c. Verbal rating scale (VRS)
d. Numerical rating Scale (NRS)
e. Faces Pain Scale (FPS)
f. Wong-Baker Faces Pain Rating Scale (WBS)
g. Full Cup Test (FCT)

\section{Multidimensional pain scales}

The intensity, nature, and location of pain can demonstrate its impact on the patient's activity or mood, and is useful to assess complex or persistent acute or chronic pain.

\subsection{MPQ [8]}

The MPQ, which was formulated in 1971 by Melzack and Torgerson., was first published in its complete form

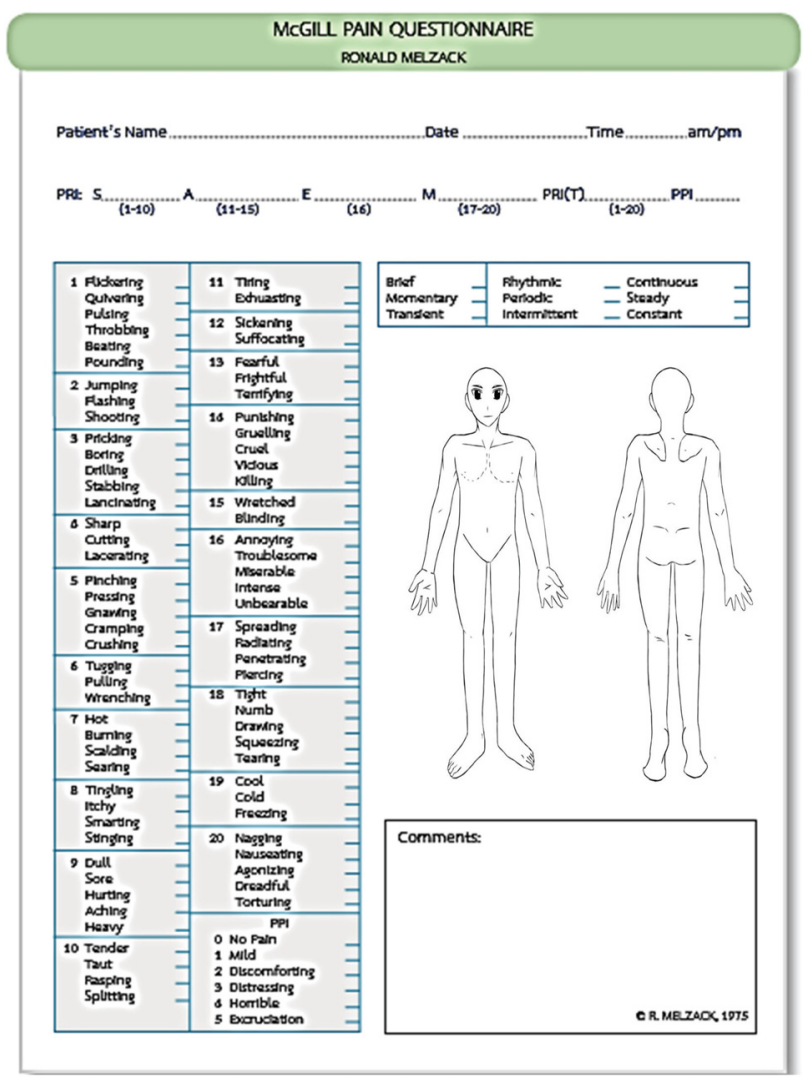

Fig. 1. Modified of McGill Pain Questionnaire. The McGill Pain Questionnaire. The descriptors fall into four major groups: sensory (S), 1-10; affective (A), 11-15; evaluative (E), 16; and miscellaneous (M), 17-20. The rank value for each descriptor is based on its position in the word set. The sum of the rank values is the pain rating index (PRI). The present pain intensity (PPI) is based on a scale of 0-5. 
Table 2. The short-form McGill pain questionnaire of Ronald Melzack [10]

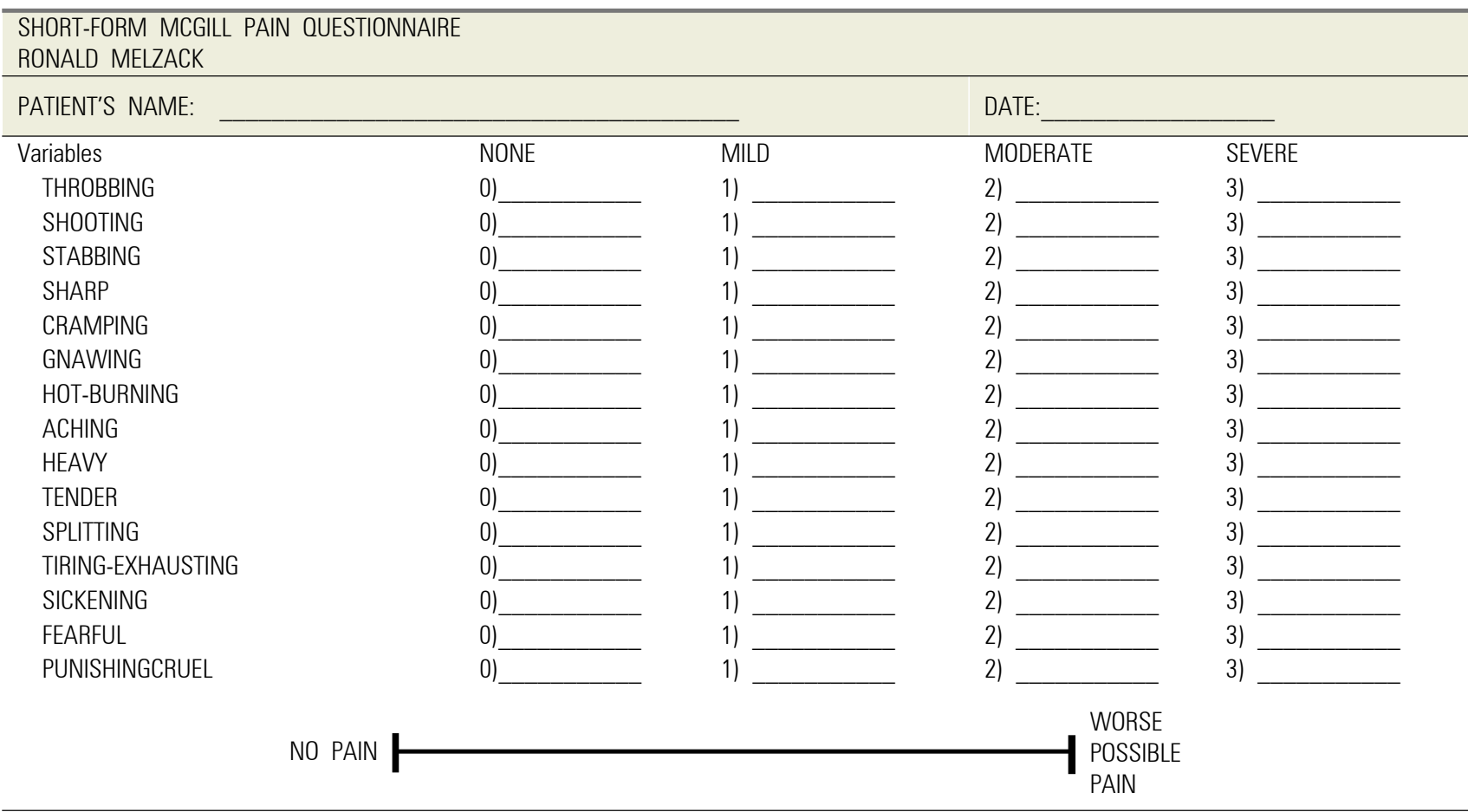

Table 3. The Present Pain Intensity (PPI) scale

\begin{tabular}{cll}
\hline \multicolumn{2}{c}{ PPI } \\
\hline Variable & \multicolumn{1}{c}{ Details } \\
\hline 0 & NO PAIN & \\
1 & MILD & \\
2 & DISCOMFORTING & \\
3 & DISTRESSING & \\
4 & HORRIBLE & \\
5 & EXCRUCIATION & \\
\hline
\end{tabular}

in 1975. As seen in Fig. 1 it measures several dimensions of the experience and intensity of pain experience and pain intensity [9]. The advantages of the MPQ are its reliability, validity, and its access to the multidimensionality of pain [9].

The major disadvantages of the MPQ include the following: very complex, requires tremendous patient compliance and endurance to fill the form, and takes up to $30 \mathrm{~min}$, which can be tedious and time-consuming [3].

\subsection{SF-MPQ (Table 2)}

SF-MPQ is the alternative scale of the Present Pain Intensity (PPI) tool (Table 3). This scale only assesses the intensity of pain, and not its other qualities [10]. It was developed in 1980, when Melzack realized that the MPQ was too long [10]. This pain assessment scale turned out to be relatively easy, since it consisted of choosing the most commonly used sensory and affective descriptors in all clinical studies. Given its simplicity, it can be applied to assess mild, moderate, and severe cases. The SF-MPQ incorporates both the PPI and VAS, and thus, has the following five sub-scores: sensory, affective, total scores from the MPQ descriptors, overall intensity scores from the PPI, and the VAS [8]. The scales were ranked as follows:
a. $0=$ none
b. 1 = mild,
c. $2=$ moderate
d. $3=$ severe

The PPI of the standard LF-MPQ and the VAS are also included to provide overall intensity scores.

\subsection{BPQ (Table 4)}

The BPQ is used to estimate the prevalence and severity of pain. It is easy to administer to a large numbers 
Table 4. The Wisconsin Brief Pain Questionnaire (modified of Wisconsin Brief Pain Questionnaire) [11]

1. On the diagram, shade in the areas where you feel pain. Put an $\mathrm{X}$ on the area that hurts most

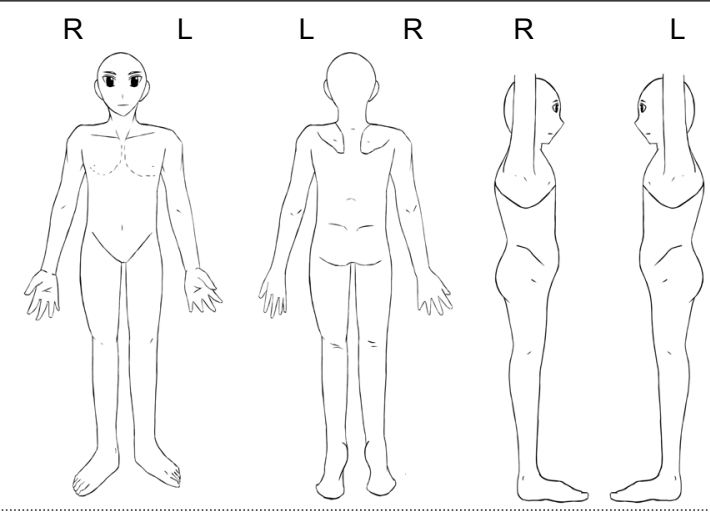

2. Please rate your pain by circling the one number that best describes your pain at its worst in the last week.
0
2
3
4
5
6
$7 \quad 8$
9
10

No pain

3. Please rate your pain by circling the one number that best describes your pain at its least in the last week.

Pain as bad as you can imagine
23
4
6
$7 \quad 8$
$\begin{array}{lll}8 & 9 & 10\end{array}$

0

Pain as bad as you can imagine

4. Please rate your pain by circling the one number that best describes your pain on average.
0
23
45
6
$7 \quad 8$
$8 \quad 9$
10

No pain Pain as bad as you can imagine
5. Please rate your pain by circling the one number that tells how much pain you have right now.
23
4
$5 \quad 6$
7
$8 \quad 9$
10

0

Pain as bad as you can imagine

6. What treatments or medications are you receiving for your pain?

7. In the last week, how much relief have pain treatments or medications provided? Please circle the one percentage that best shows how much relief you have received.
$0 \%$
$10 \%$
$20 \% \quad 30 \%$
$40 \%$
$50 \%$
$60 \%$
$70 \%$
$80 \%$
$90 \%$
$100 \%$

No relief

8. Circle the one number that describes how, during the past week, pain has interfered with your:

a. General activity
0

$$
2
$$
3
4
5
6

7

8

Complete relief

Does not interfere

b. Mood

\begin{tabular}{|c|c|c|c|c|}
\hline 0 & 1 & 2 & 3 & 4 \\
\hline \multicolumn{5}{|c|}{ c. Walking ability } \\
\hline 0 & 1 & 2 & 3 & 4 \\
\hline
\end{tabular}

e. Relations with other people

$\begin{array}{ccccc}0 & 1 & 2 & 3 & 4 \\ \text { f. Sleep } & & & & \\ 0 & 1 & 2 & 3 & 4\end{array}$

g. Enjoyment of life

$\begin{array}{ll}0 & 1\end{array}$

Does not interfere

$\begin{array}{llll}2 & 3 & 4 & 5\end{array}$

5

5

5

5

5

5

6

$6 \quad 7$

6

6

6

6

6

6

$(2+2$

Detail:
Brief Pain Inventory Scoring Instructions

1. Pain Severity Score: This is calculated by adding the scores for questions 2, 3, 4 and 5 and then dividing by 4.This gives a severity score out of 10 .

2. Pain Interference Score: This is calculated by adding the scores for questions $8 \mathrm{a}, \mathrm{b}, \mathrm{c}, \mathrm{d}, \mathrm{e}, \mathrm{f}$ and $\mathrm{g}$ and then dividing by 7 . This gives an interference score out of 10 .

Brief Pain Inventory from Hunter Integrated Pain Service Dec 2006

Reproduced with acknowledgement of the Pain Research Group the University of Texas MD Anderson Cancer Center, USA 


\section{No pain}

Pain as bad as it Could possibly be

Fig. 2. The visual analog scale (VAS).

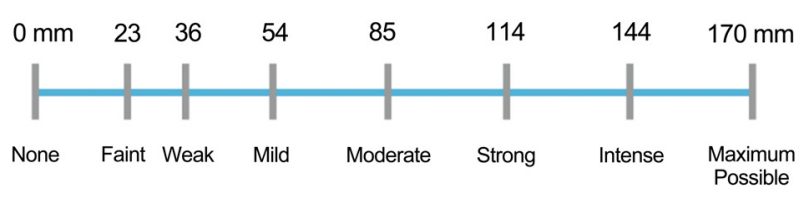

Fig. 3. Heft-Parker visual analog scale (HPS).

of patients, since it brief, can be self-administered, and easily determines the history, intensity, location, cause, quality, and interference with activities. However, the disadvantage is that given its brevity, it does not allow a comprehensive assessment of the pain course [11].

\section{Unidimensional scales}

Most previous acute pain researches [5] used these pain measurement tool for only the sensory pain experience.

\subsection{VAS}

In OMFS research the VAS is commonly used to investigate many kinds of subjective experience, including pain [5]. The VAS (Fig. 2) is a straight, $100-\mathrm{mm}$ line $(10 \mathrm{~cm})$, which can either be vertical or horizontal. It represents continuous pain intensity, where the left end of the line indicates "no pain," while the other end denotes "pain as bad as it could possibly be." A patients indicates their level of pain (in $\mathrm{mm}$ ), by marking a single point on the line [9].

\subsection{HPS}

The HPS is similar to the VAS, except that it is 170 $\mathrm{mm}$ in length and includes various descriptors, which help interpret the data, as follows [12] (Fig. 3):

a. no pain is represented as $0 \mathrm{~mm}$ on the scale

b. mild pain is defined as $>0$ to $<54 \mathrm{~mm}$, which include the descriptors of faint

c. weak, mild, and moderate pain is defined as $>54$ to $<114 \mathrm{~mm}$

d. severe pain is defined as $\geq 114 \mathrm{~mm}$ and include the

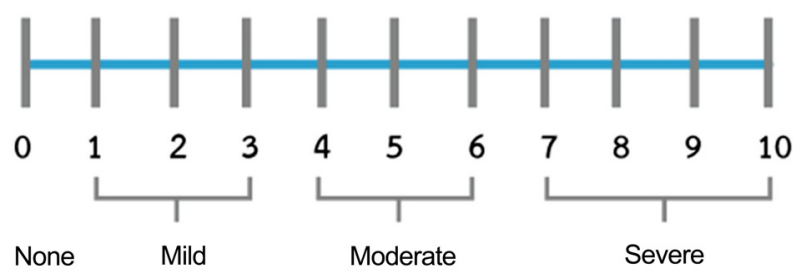

Fig. 4. Numerical rating Scale (NRS) [14]

descriptors of strong, intense, and maximum possible

\subsection{VRS or VDS}

The VRS or VDS was created by Keele [13]. It was developed to assess patient responses to analgesics [9], with statistical validity and reliability. The VRS lists adjectives describing different levels of pain intensity [5], which consists of five numerically ranked words representing intensity of pain including the following [9]:
a. 1: none
b. 2: mild
c. 3: moderate
d. 4: severe
e. 5: Unbearable

The VRS is short and simple, making it easy to complete. Nonetheless, it can be used to measure both acute and chronic pain [9] and is suitable for every group of patients, particularly older ones [5].

\subsection{NRS (Fig. 4)}

The NRS, which was developed by Downie [14] in 1978, consists of a vertical or horizontal line, with a total of 11 numbers, ranging from 0 to 10 , denoting no pain to the worst possible pain, respectively [7]. Previous studies using the NRS offer great accuracy [9]. The NRS is a simple assessment tool that is easy to score. It can be administered in either the written or verbal form [9], but is not suitable for the elderly or very young child as it does not differentiate words and numbers [9]

\subsection{FPS (Fig. 5)}

The original FPS was a 7-point number scales, which was more difficult to complete since it did not follow the usual $0-5$ or $0-10$ metric [15]. Thus, Hicks et al. 


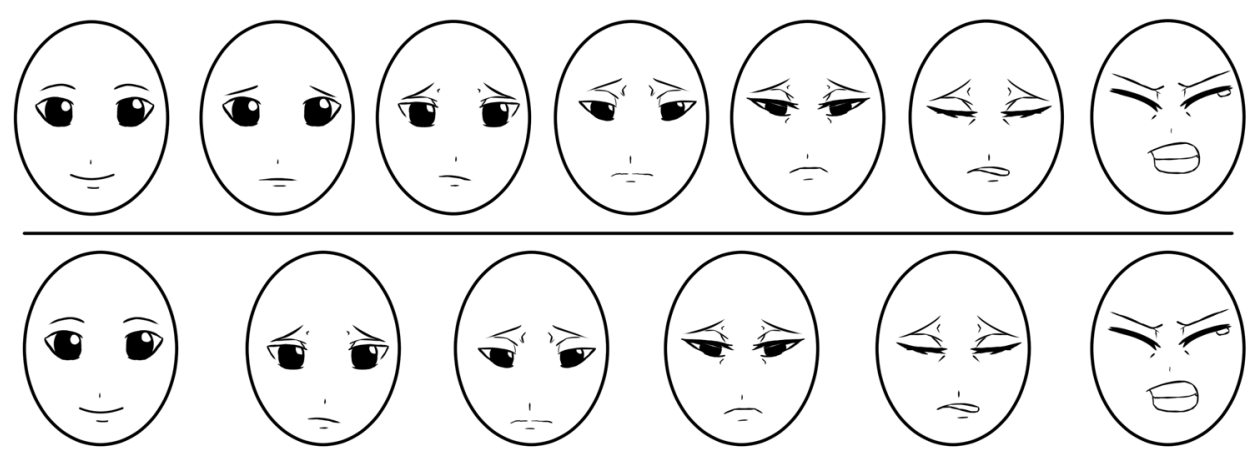

Fig. 5. Faces Pain Scale (FPS) (modified of Faces Pain Scale) [15].

Top: Faces Pain Scale scored 0 to 6. Bottom: Faces Pain Scale-Revised, scored 0-2-4-6-8-10 (or 0-1-2-3-4-5).

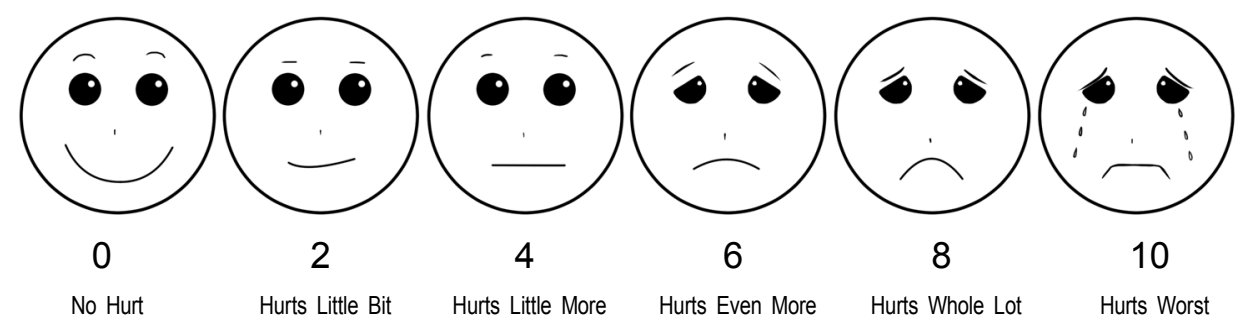

Fig. 6. Wong-Baker Faces Pain Rating Scale (WBS) (modified Wong-Baker Faces Pain Rating Scale) [16].

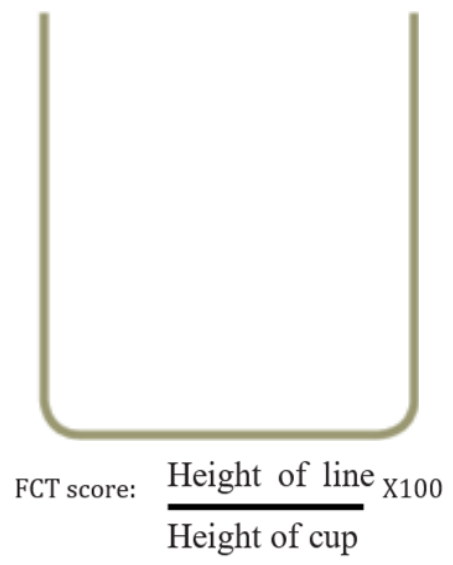

Fig. 7. Full Cup Test [18].

revised the FPS scale, changing it to a more suitable 0-10 scale. Bieri et al. however, developed this measurement as seven line-drawn faces in a horizontal format, ranging from no pain to worst pain [15]. Instead of a happy face, a neutral face, with the absence of smiles and tears, was used to depict no pain [7], with increasing levels of pain intensity along the remaining six-face continuum. Patients were asked to point to the face that best represented the intensity of their pain. The scores $0,2,4,6,8$, and 10 were assigned to each face consecutively from no pain to more painful faces [7].

\subsection{WBS}

Wong and Baker [16] created the WBS (Fig. 6), which shows faces ranging from a happy face at 0 ("no pain") to a crying face at 10 ("worst pain"). Since patients are required to point to the face that best describes their feelings of pain, it is a popular method of pediatric pain assessment [17].

\subsection{FCT}

Ergun et al. [18] described the FCT a simple "cup" drawing. Patients are required to draw a completely full cup for the most severe pain, an empty cup for no pain at all, and a horizontal line in the cup to represent pain levels between [18]. The FCT score is calculated as a percentage (Fig. 7).

\section{DISCUSSION}

Pain that occurs during or post-OMFS can be difficult to assess. Since patient self-reports are accepted as the gold standard for pain assessment [19], pain assessment 
tools should be simple and straight-forward to use [6]. These tools should ideally measure baseline discomfort and the response to remedy [17].

Several previous articles in biomedical studies suggested the use of multidimensional scales to assess chronic pain, such as in cancer and lower back pain $[6,8,10,11]$, since it can be more difficult to assess than acute pain [6].

Sensory and affective pain can be relatively easily described using the simple intensity sub-scales of the SF-MPQ, which includes the PPI and VAS. The SF-MPQ is more commonly used instead of the MPQ because the latter measures several dimensions of the experience and intensity of pain, making it more complicated to use [9]. The BPQ for estimating the prevalence and severity of pain can be easily administered to a large number of patients. The BPQ can be a quantitative or qualitative measure of pain, and is thus, the best clinical pain measurement tool.

Several previous articles suggested the use of unidimensional scales to measure acute pain [5,6,20-25], caused by trauma, surgery, childbirth, or an acute medical disease. Previous OMFS articles mostly used the VAS for pain assessment in acute pain. Bijur et al. [26] found that the VAS was a highly reliable tool for assessing acute pain in adults. Garra et al. [17] demonstrated that the VAS was also more informative and relatively sensitive to changes in pain, compare to other ordinal scales. The VAS tool is recommended for measuring pre- and post-operative pain. Additionally, although the VAS is similar to the NRS, it is more sensitive. Although the NRS can both underestimate and overestimate scores than the VAS, however, it is easy to administer verbally in a clinical unit and is familiar as a clinical tool [27]. Polly et al. [27] suggested that the verbally administered the NRS can be related to the VAS in acute pain measurement. Unfortunately, the VAS has also been mentioned to have more practical difficulties than the VRS and the NRS [20].

The VRS can be applied by mail or telephone [21] and it separates the pain experience into distinct cate- gories. However, since the intervals of the VRS are not equally spaced, it cannot be assumed to be equal to ordinal data. Another weak point of the VRS scale is that application of statistical analysis to nonparametric scales is limited [5].

Previous studies suggest the use of FPS for children and older people [6,9,15-17,28-29], since children find it easier to comprehend than non-graphics-based pain assessment scales [20]. The larger number of faces and consequent finer distinctions, however, pose difficulty for children aged 3-5 years [29].

Stanford et al. [17] demonstrated that age is a significant predictor of a child's ability to accurately apply the FPS. The WBS is one of several faces scales that has been used in multiple pediatric pain assessment settings [17]. Given the lack of tools for older people, some researchers have also suggested the use of the WBS for this population. The FPS is self-reporting scale that uses facial expressions to assess pain intensity [30]. This has appropriate psychometric properties when used with the elderly [30]. The FPS-R, however, also has strong validity and reliability properties, and has been recommended to measure pain intensity in elderly adults [30].

The full cup test is useful for pain assessment of patients with low-education patients because it does not need any numerical or verbal skills and is easy to understand and complete the scale [20].

The common intervention sequelae in lower third molar intervention (LTMI) is associated with post-operative pain, swelling, infection, and limited mouth opening. All of these may be decreased with antibiotic regimens and anti-inflammatory drugs. Previous reviews of analgesic efficacy for control pain after all types of third molar surgery contain a significant number of clinical trials of the third molar intervention study [31], and several contain pain assessment after analgesic drug usage following LTMI. The studies were shown less analgesic drug usage relate to less post-operative pain or more analgesic drug usage correlate with more painful after surgery [32].

The VAS is the most common scale to evaluate post- 
operative pain (especially after LTMI) [33]. Apart from due to the surgery itself, post-operative acute pain can occur due to insufficient administration of local anesthesia. In 2005, Babatunde et al. [34] compared the effect of co-administered dexamethasone and diclofenac potassium (diclofenac $\mathrm{K}$ ) with diclofenac $\mathrm{K}$ alone, on postoperative pain, swelling, and limited mouth opening following LTMI. They evaluated the pain score through a four-point Category Rating Scale as follows:

a. 0: no pain" (patient experiences no discomfort)

b. 1: mild pain" (almost unnoticeable pain)

c. 2: moderate pain" (noticeable pain, but patient can still engage in routine daily activities)

d. 3: severe pain" (very noticeable pain which disturbs the patient's daily routine)

In 2013, Marko et al. [35] also assessed the intensity postoperative pain during the first seven days after LTMI using the VAS. Fenlon et al. [36] determined the effect of pre-operative paracetamol administration on pain following LTMI, using the VAS, 1 hour after the intervention [36]. In 2017, Raiesian et al. [37] assessed the effect of low-level laser therapy (LLLT) on pain in LTMI, by complete a questionnaire with the VAS for pain intensity measurement. Further, Nicoli et al. [38] studied the efficacy of two different anti-inflammatory agents, i.e., Diclofenac (Deltaflogin) and Lumiracoxib (Prexige), in postoperative pain control resulting from LTMI, and also assessed pain using the VAS, as did Huskisson in 1983 [39]. The pain measurement scale also consists of a 100-mm straight line, which allows quantification of the post-operative pain.

In 2016, de Oliveira et al. [40] compared the efficacy of ibuprofen and etodolac for controlling pain after extraction of lower third molars and assessed pain using an 11-point VAS scale. They used a line with 11 identical boxes, where the extremes represented the pain limitation of patients, from absent to severe, respectively. At 6,12 , and $24 \mathrm{~h}$ after the LTMI, patients were instructed to mark an $\mathrm{X}$ in the box on the scale to indicate their pain intensity. This study demonstrated that successful use of this tool, which was adapted so that the patient had an increased understanding of the scale. Baxendale et al. in 1993 [41] evaluated the effect of a single prophylactic dose of oral dexamethasone $8 \mathrm{mg}$ on these complications, in a randomized double-blind study of 50 adult patients. They also used the VAS for post-operative pain assessment in all patients of this study. In 2017, Boonsiriseth et al. [42] showed the effects of $8 \mathrm{mg}$ dexamethasone injection into the pterygomandibular space on the postoperative sequelae of lower third molar surgery. They analyzed the consumption of analgesics and assesses pain using the VAS.

In 2012, Aznar-Arasa et al. [43] performed the comparative study of the analgesic and anti-inflammatory effects of preoperative and postoperative administration of ibuprofen following LTMI. They measured the intensity of postoperative pain using a 100-mm VAS scale. The intensity of pain was assessed every $2-4 \mathrm{~h}$ for the first $14 \mathrm{~h}$, and then every $8 \mathrm{~h}$ between, 24 and 64 $\mathrm{h}$ post-surgery.

In 2012, de Santana-Santos et al. [44] investigated the relationship between preoperative findings and short-term outcome following LTMI. In this study, pain intensity was evaluated using a 10-level VAS scale. In 2010, Barreiro-Torres et al. [45] studied the difficulty and technique LTMI, assessing the ability level of fourteen dental practitioners with varying levels of experience. They also used a 100-mm VAS scale and a modified version of a surgical difficulty scale.

A study conducted by Ozveri Koyuncu et al. [46], in 2013, on postoperative pain, also used a 10-cm VAS scale. In 2015, Nedal et al. [47] studied the effects of primary versus secondary wound closure on postoperative pain, swelling, and acute alveolar osteitis after surgical extraction of partially LTMI. They also used the VAS for pain intensity assessment in all volunteers.

In contrast, in 2013, Anighoro et al. [48] assessed baseline and postoperative pain (following LTMI), using a four-point VRS verbal rating scale from 0 to 3. In 2017, Gulüen et al. [49] evaluated the efficacy of platelet-rich fibrin (PRF) on postoperative edema and pain after impacted mandibular third molar surgery using both the 
VAS and VRS. All patients completed the VAS and VRS to assess their pain, and there was no significant differences between the two pain scores. It must be noted, however, that the NRS is easier to use to evaluate pain in adults [33]. Further, the WBS is widely applied to assess pain in children and older adults.

In conclusion, multidimensional scales such as MPQ, SF-MPQ, and BPQ are suitable to assess chronic pain, while unidimensional scales, like the VAS, VDS, VRS, NRS, FPS, WBS, and FCT are more suitable for acute pain evaluation occurring after LTMI.

\section{AUHOR OROIIS}

Nattapong Sirintawat: https://orcid.org/0000-0002-6441-5243

Kamonpun Sawang: https://orcid.org/0000-0003-3921-0307

Teeranut Chaiyasamut: https://orcid.org/0000-0003-0487-5333

Natthamet Wongsirichat: https://orcid.org/0000-0003-3005-2680

ACKNOWLEDGEMENTS: The authors would like to thank the staff and dental assistants, including co-workers at the Department of Oral and Maxillofacial Surgery, Faculty of Dentistry, Mahidol University.

DECLARATION OF INTERESTS: The authors have no conflicts of interest.

FUNDING: none

CONFLICT OF INTEREST: none

ETHICS APPROVAL: not required

\section{REFERENCES}

1. Todd KH, Ducharme J, Choiniere M, Crandall CS, Fosnocht DE, Homel P, et al. Pain in the emergency department: results of the pain and emergency medicine initiative (PEMI) multicenter study. J Pain 2007; 8: 460-6.

2. Merskey H. Classification of chronic pain: description of chronic pain syndromes and definition of pain terms. Pain 1986; Suppl 3: S1-S225.

3. McAloon C, O'Connor PC, Boyer M. Patient's perception of pain on admission and discharge from the emergency department. N J Nurse 2003; 33: 7.
4. Closs SJ, Gardiner E, Briggs M. Outcomes of a nursing intervention to improve postoperative pain at night. Acute Pain: Int J Acute Pain Manage 1998; 1: 22-31.

5. Briggs M, Closs JS. A descriptive study of the use of visual analogue scales and verbal rating scales for the assessment of postoperative pain in orthopedic patients. J Pain Symptom Manage 1999; 18: 438-46.

6. Breivik H, Borchgrevink PC, Allen SM, Rosseland LA, Romundstad L, Breivik Hals EK, et al. Assessment of pain. Br J Anaesth 2008; 101: 17-24.

7. Li L, Liu X, Herr K. Postoperative pain intensity assessment: a comparison of four scales in Chinese adults. Pain Med 2007; 8: 223-34.

8. Melzack R. The McGill Pain Questionnaire. Anesthesiology 2005; 103: 199-202.

9. Flaherty SA. Pain measurement tools for clinical practice and research. AANA J 1996; 64: 133-40.

10. Melzack R. The short-form McGill Pain Questionnaire. Pain 1987; 30: 191-7.

11. Daut RL, Cleeland CS, Flanery RC. Development of the Wisconsin Brief Pain Questionnaire to assess pain in cancer and other diseases. Pain 1983; 17: 197-210.

12. Heft MW, Parker SR. An experimental basis for revising the graphic rating scale for pain. Pain 1984; 19: 153-61.

13. Keele KD. The pain chart. Lancet 1948; 2: 6-8.

14. Downie WW, Leatham PA, Rhind VM, Wright V, Branco JA, Anderson JA. Studies with pain rating scales. Ann Rheum Dis 1978; 37: 378-81.

15. Bieri D, Reeve RA, Champion GD, Addicoat L, Ziegler JB. The Faces Pain Scale for the self-assessment of the severity of pain experienced by children: Development, initial validation, and preliminary investigation for ratio scale properties. Pain 1990; 41: 139-50.

16. Cote CJ, Lerman J, Anderson B. A practice of anesthesia for infants and children. 5th ed. Elsevier Health Sciences. 2013, pp 940.

17. Garra G, Singer AJ, Taira BR, Chohan J, Cardoz H, Chisena E, et al. Validation of the Wong-Baker FACES Pain Rating Scale in Pediatric Emergency Department Patients. Acad Emerg Med. 2010; 17: 50-4.

18. Ergun U, Say B, Ozer G, Yildirim O, Kocaturk O, Konar 
$\mathrm{D}$, et al. Trial of a new pain assessment tool in patients with low education: the full cup test. Int J Clin Pract 2007; 61: $1692-6$

19. McCahon S, Strong J, Sharry R, Cramond T. Self-report and pain behavior among patients with chronic pain. Clin J Pain 2005; 21: 223-31.

20. Odai ED, Ehizele AO, Enabulele JE. Assessment of pain among a group of Nigerian dental patients. BMC Res Notes 2015; 8:251.

21. Isik K, Unsal A, Kalayci A, Durmus E. Comparison of three pain scales after impacted third molar. Oral Surg Oral Med Oral Pathol Oral Radiol Endo 2011; 112: 715-8.

22. Lara-Munoz C, De Leon SP, Feinstein AR, Puente A, Wells CK. Comparison of three rating scales for measuring subjective phenomena in clinical research. I. Use of experimentally controlled auditory stimuli. Arch Med Res 2004; 35: $43-8$.

23. Gagliese L, Weizblit N, Ellis W, Chan VW. The measurement of postoperative pain: A comparison of intensity scales in younger and older surgical patients. Pain 2005; 117: 412-20.

24. Sloman R, Wruble AW, Rosen G, Rom M. Determination of clinically meaningful levels of pain reduction in patients experiencing acute postoperative pain. Pain Manag Nurs 2006; 7: 153-8.

25. Bech RD, Lauritsen J, Ovesen O, Overgaard S. The Verbal Rating Scale Is Reliable for Assessment of Postoperative Pain in Hip Fracture Patients. Pain Res Treat 2015; 2015: 676212.

26. Bijur PE, Silver W, Gallagher EJ. Reliability of the visual analog scale for measurement of acute pain. Acad Emerg Med 2001; 8: 1153-7.

27. Bijur PE, Latimer CT, Gallagher EJ. Validation of a verbally administered numerical rating scale of acute pain for use in the emergency department. Acad Emerg Med 2003; 10: 390-2.

28. Goodenough B, Champion GD, von Baeyer C, Ziegler JB. Facial expression scales for self-report of pain by children: rationale, validity and utility. Paper presented at the Fourth International Symposium on Pediatric Pain, 1997.
29. Shih AR, von Baeyer CL. Preschool children's seriation of pain faces and happy faces in the Affective Facial Scale. Psychol Rep 1994; 74: 659-65.

30. Miro J, Huguet A, Nieto R, Paredes S, Baos J. Evaluation of reliability, validity, and preference for a pain intensity scale for use with the elderly. J Pain 2005; 6: 727-35.

31. Coulthard P, Patel N, Bailey E, Coulthard MB. Measuring pain after oral surgery. Oral Surgery 2014; 7: 203-8.

32. Seymour RA. The use of pain scales in assessing the efficacy of analgesics in post-operative dental pain. Europ J Clin Pharmacol 1982; 23: 441-4.

33. Ferreira-Valente MA, Pais-Ribeiro JL, Jensen MP. Validity of four pain intensity rating scales. Pain 2011; 152: 2399-404.

34. Bamgbose BO, Akinwande JA, Adeyemo WL, Ladeinde AL, Arotiba GT, Ogunlewe MO. Effects of co-administered dexamethasone and diclofenac potassium on pain, swelling and trismus following third molar surgery. Head Face Med 2005; 1: 11.

35. Matijević M, Uzarević Z, Gvozdić V, Mikelić VM, Leović D, Macan D. The influence of surgical experience, type of instructions given to patients and patient sex on postoperative pain intensity following lower wisdom tooth surgery. Acta Clin Croat 2013; 52: 23-8.

36. Fenlon S, Collyer J, Giles J, Bidd H, Lees M, Nicholson $\mathrm{J}$, et al. Oral vs intravenous paracetamol for lower third molar extractions under general anaesthesia: is oral administration inferior? Br J Anaesth 2013; 110: 432-7.

37. Raiesian S, Khani M, Khiabani K, Hemmati E, Pouretezad M. Assessment of low-level laser therapy effects after extraction of impacted lower third molar surgery. J Lasers Medl Sci 2017; 8: 42-5.

38. Nicoli GA, Conte-Neto N, Campos JADB, CabriniGabrielli MA, Pereira-Filho VA. Efficacy of lumiracoxib versus diclofenac sodium in pain control following extraction of impacted lower third molar. Int J Odontostomat 2017; 11: 47-51.

39. Huskisson EC. Visual analogue scales. In: Pain measurement and assessment. Edited by Melzack R. New York, Raven Press. 1983 pp 33-37.

40. Silva de Oliveira JC, Grossi de Oliveira GA, Bassi AP. 
Comparative Assessment of the Effect of Ibuprofen and Etodolac on Edema, Limited mouth opening, and Pain in Lower Third Molar Surgery: A Randomized Clinical Trial. J Oral Maxillofac Surg 2016; 74: 1524-30.

41. Baxendale BR, Vater M, Lavery KM. Dexamethasone reduces pain and swelling following extraction of third molar teeth. Anaesthesia 1993; 48: 961-4.

42. Boonsiriseth K, Latt MM, Kiattavorncharoen S, Pairuchvej $\mathrm{V}$, Wongsirichat N. Dexamethasone injection into the pterygomandibular space in lower third molar surgery. Int J Oral Maxillofac Surg 2017; 46: 899-904.

43. Aznar-Arasa L, Harutunian K, Figueiredo R, ValmasedaCastellon E, Gay-Escoda C. Effect of preoperative ibuprofen on pain and swelling after lower third molar removal: a randomized controlled trial. Int $\mathrm{J}$ Oral Maxillofac Surg 2012; 41: 1005-9.

44. de Santana-Santos T, de Souza-Santos JA, Martins-Filho PR, da Silva LC, de Oliveira e Silva ED, Gomes AC. Prediction of postoperative facial swelling, pain and limited mouth opening following third molar surgery based on preoperative variables. Med Oral Patol Oral Cir Bucal 2013;
18: e65-70.

45. Barreiro-Torres J, Diniz-Freitas M, Lago-Mendez L, GudeSampedro F, Gandara-Rey JM, Garcia-Garcia A. Evaluation of the surgical difficulty in lower third molar extraction. Med Oral Patol Oral Cir Bucal 2010; 15: e869-74.

46. Koyuncu BÖ, Zeytinoğlu M, Çetingül E. Comparison of 2 different flap techniques in the surgical removal of bilateral impacted mandibular third molars. Turk J Med Sci 2013; 43: 891-8.

47. Nedal AM. The effects of primary and secondary wound closure following surgical extraction of lower third molars on post-operative morbidity: A prospective randomized clinical trial. J Dent Oral Hygiene 2015; 7: 168-74.

48. Anighoro EO, Gbotolorun OM, Adewole RA, Arotiba GT, Effiom OA. Assessment of the effect of wound closure technique on postoperative sequaele and complications after impacted mandibular third molar extraction. Open J Stomatol 2013; 3: 527-32.

49. Gülşen U, Şentürk MF. Effect of platelet rich fibrin on edema and pain following third molar surgery: a split mouth control study. BMC Oral Health 2017; 17: 79. 